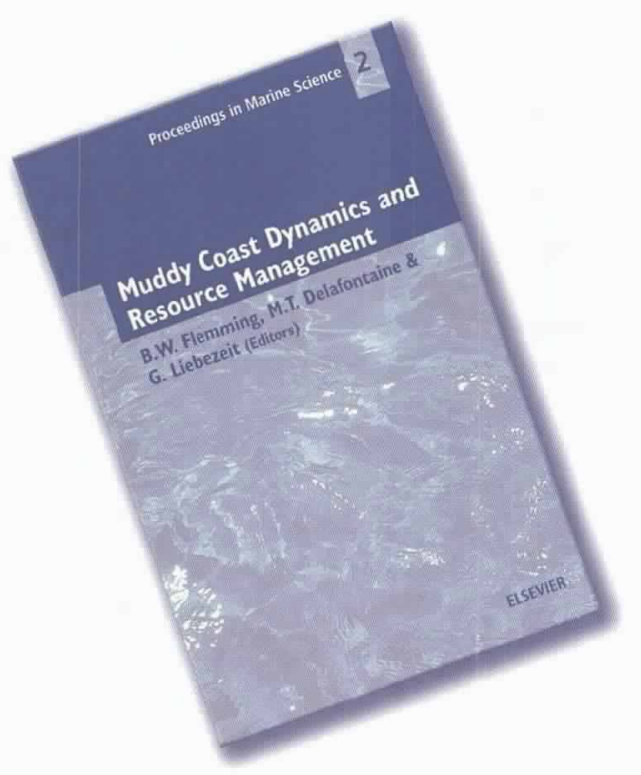

\section{Muddy Coast Dynamics and Resource Management}

Edited by B.W. Flemming, M.T. Delafontaine and G. Liebezeit

Elsevier Science

ISBN 0-444-50464-8, 294 pages

\section{Review by}

Donald Scavia

National Oceanic and Atmospheric Administration

Silver Spring, Maryland USA

We are all accustomed to statistics about how many people live near the coasts (53\% living within U.S. coastal counties; $75 \%$ globally within $100 \mathrm{~km}$ of the coast); however, it is also becoming clear that among the types of coastal environments most threatened by social and natural stresses, shallow-water environments are particularly susceptible. Clear-water environments (e.g. coral reefs) lie at one end of the shallow-water spectrum; and muddy-waters at the other. While corals have seen increasing attention from the science and management communities in recent years, this volume focuses on the muddier end of the spectrum. In the preface to this new book from Elsevier's "Proceedings in Marine Science" series, the editors define these muddy coasts as "land-sea transitional environments commonly found along low-ener- gy shorelines which either receive large annual supplies of muddy sediments, or where unconsolidated muddy deposits are being eroded by wave action." These areas, representing vast expanses of mangroves, salt marshes, and shores of estuaries and lagoons, are threatened not only from direct (e.g. fishing, aquaculture) and indirect (agriculture, development) human use and, but also from the slowly encroaching sea caused by increasing rates of sea level rise.

This partial proceedings of a conference held in Germany in September 1997 draws attention to some of the key dynamics, albeit primarily geophysical, that control many of the key processes in these shallow ecosystems. With its as yet unpublished SCOR report, "Muddy Coasts of the World: Processes, Deposits, and Function", the two volumes should provide a solid sampling of state-of-the-science case studies from around the world.

The volume reviewed here includes case studies from Germany, the United Kingdom, Portugal, U.S., Cameroon, Tanzania, Korea, and China, although over half are from Germany. The papers were all peer reviewed prior to publication and their quality reflects that. The results of thorough editing and proof reading are clearly evident. The common format among papers and clear writing style made for easy reading and comprehension. I found only one minor format problem (the axis labels for figures on page 280 were hard to read) and one humorous (I hope) typographical error. In the preface, the editors indicated that support from SCOR was "last but least". I assume "not" was missing.

The papers are presented in five sections. The first focuses on hydrodynamics and suspended particulate matter in bays and back-barrier tidal basins of Tanzania, The Wash (U.K.), and in the East Frisian Wadden Sea. The papers include discussions of the effects of tidal asymmetries on sediment flux and erosion in mangroves and mud flats, and a demonstration of the use of towed, high frequency acoustic Doppler current profilers (ADCPs) for estimating large-scale mass transport of suspended particulates. The second section includes three papers on erosion, deposition, and sediment budgets of tidal basins focused along the German coast of the East Frisian Wadden Sea. They include an evaluation of the relative effects of oxic and anoxic conditions on sediment erosion and the use of sequential, relatively high-resolution maps of sediment elevation and content to determine short- and long-term dynamics and recovery from episodic events. Also included in this section is a thorough review of relationships among sediment erosion shear strength and erosion rate, and a proposed screening model for estimating values of the 
erosion rate constant for inorganic and organic-rich sediments where field observations are unavailable.

Section 3 includes six papers on primary production, nutrient fluxes, and mineralization in shallow coastal lagoons of the Baltic Sea. This collection of papers include studies of the significance of microphytobenthos primary production; benthic microbial decomposition and mineralization of organic carbon; and dynamics and controls of benthic fluxes of iron, manganese, methane, nitrous oxide, oxygen, and nutrients. These excellent studies were all conducted in the same geographic area and many of the co-authors overlapped. I was a bit disappointed that the editors did not take the opportunity to provide an integration or synthesis for this section. It would have added considerable to the book. Section 4 contained two papers; one on the effects of plant roots on immobilizing zinc and lead ions in the Tagus estuary (Portugal), and one on the use of the elemental composition of historically distant deposits in reconstructing paleoenvironments along the west coast of Korea.

The final section includes six papers focused on sea level rise and land reclamation case studies from Cameroon, China, and the Wadden Sea. The Cameroon case study is an interesting and quite thorough, albeit speculative, integration of the potential effects of sea level rise on coastal fisheries, including suggestions for adaptation and response. Two papers address the effects of land reclamation in China on sea-level-rise impacts and the potential impacts of sea level rise, sediment supply, and resulting altered current and tide regimes on coastal structures. The two papers on the Wadden Sea "squeeze" (i.e., the loss of space for settlement of finegrained material) reconstruct theoretical sediment type distributions, in the absence of dikes, to explore their impacts, as well as those of continued sea level rise on the lack of mud flats and organic matter in these tidal basins. The final paper uses two land-reclamation case studies from China to describe application of the principles of Integrated Coastal Area Management.

My only disappointment in this otherwise excellent book was that it did not seem to live up to its title that includes reference to "resource management". While there were some movements in that direction in a few of the papers, it did not seem to be the primary focus anticipated in the title. Many of the papers could have taken a step closer to that science/management interface. As a proceedings volume, this one was better than most; peer reviews and careful editing make a positive difference. I recommend this survey of case studies that explore the dynamics of muddy coastal environments to specialists in these areas, as well as to those with a more general interest in how these processes impact use and sustainability of these environments. [d

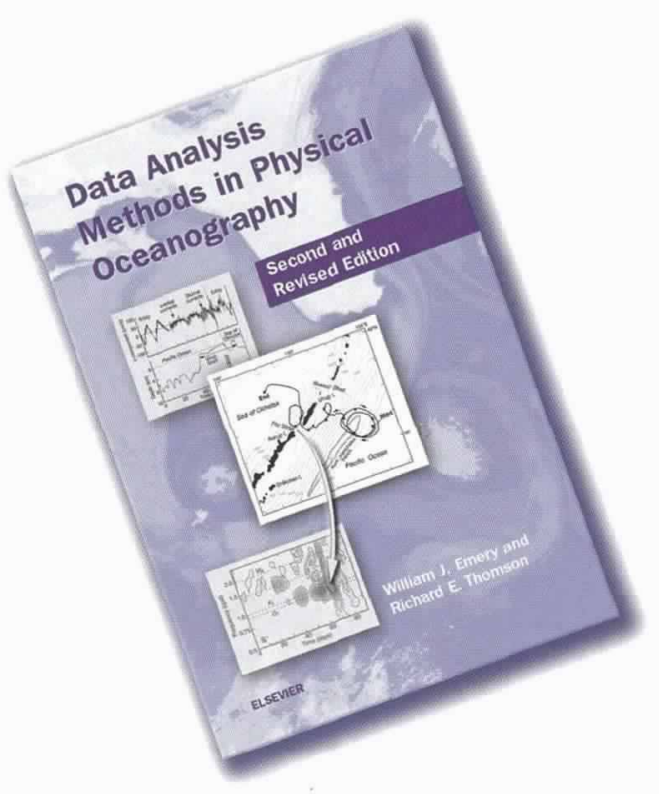

\section{Data Analysis Methods in Physical Oceanography}

\author{
Second, Revised Edition \\ by W.J. Emery and R.E. Thompson \\ Elsevier Science \\ ISBN 0-444-50757-4, 658 pages

\section{Review by \\ Al Plueddemann \\ Woods Hole Oceanographic Institution \\ Woods Hole, Massachusetts USA}

A previous review (Oceanography, 1999, 12[3], 53-54) described the contents of the first edition in detail, and praised the book as the most comprehensive and practical source of information on data analysis methods available to the physical oceanographer. Both the detailed description and the high praise remain applicable to the second edition, which is nearly identical to the first.

The most significant change is that the second edition is available in paperback at about $40 \%$ of the hardcover cost. The lower price should help to get this excellent resource in the hands of more scientists, teachers, and students.

Minor changes in the second edition include the correction of about a dozen typos and other errors, the revision of half a dozen equations with missing or erroneous terms, and several modifications and additions meant to clarify meaning. A few more significant errors in equations, matrices, and tables have also been corrected (most notably in the section on harmonic analysis using the method of least squares). The second edi- 